\title{
Takayasu Arteritis Involving Multiple Peripheral Arteries of a 37-year-old Female: A Case Report and Brief Overview
}

\author{
Md. Faruque ${ }^{1}$, M A Rashid², Md. Tanveer Faruk ${ }^{3}$, Md. Jabed Iqbal ${ }^{4}$, F Rahman $^{5}$
}

\begin{abstract}
:
Takayasu arteritis, formerly known as "pulseless disease", is a chronic idiopathic vasculitis which affects the large vessels in the body. First described in the 1800 's, this rare condition is more commonly found in Asian women in their 40's. Herein, we report the case of a young woman whose exertional angina and claudication were the initial presentation of active Takayasu arteritis. The importance of modern technology of imaging such as CT, MRI and angiography, can often have paramount importance for confirming a diagnosis and the extent of the pathology.
\end{abstract}

Newer modalities of investigation helps in evaluation of vascular involvement and its haemodynamic effects on cardiovascular system. Previously majority of patient had to be diagnosed clinically. Now a days by CT peripheral Angiogram this disease can be diagnosed. Invasive procedure of peripheral Angiogram is troublesome but single IV dye injection can revealed the actual scenario. So it has got important scientific value.

Key Word: Pulse less, Arteritis, Immunosuppressive, Stenosis.
Introduction:

Takayasu arteritis is a rare, systemic, inflammatory large vessel vasculitis of unknown aetiology that most commonly affects women of childbearing age. It is defined as "granulomatous inflammation of the aorta and its major branches" by the Chapel Hill consensus conference on the nomenclature of systemic vasculitis. ${ }^{1}$ Because of its predilection for the brachiocephalic vessels, this arteritis has been labeled pulseless disease and aortic arch syndrome. ${ }^{2}$ Takayasu arteritis is commonly occurs in women younger than $50 \mathrm{yrs}$ of age and can manifest as isolated, atypical and/or catastrophic disease. It can involve any or all of the major organ systems. The disease has been reported in all

1. Professor of Cardiology, Anwer Khan Modern Medical College (AKMMC), Dhaka.

2. Associate Professor, Department of Anatomy, Bangladesh Medical College, Dhaka.

3. Lecturer, Physiology, Marks Medical College, Dhaka.

4. Junior consultant, Cardiology, Anwer Khan Modern Medical College (AKMMC), Dhaka.

5. Professor of Cardiology, Bangabandhu Sheikh Mujib Medical University (BSMMU), Dhaka. parts of the world, although it appears to be more prevalent in Asians. Takayasu arteritis is observed more in patients of Asian or Indian descent. Japanese patients with Takayasu arteritis have a higher incidence of aortic arch involvement. In contrast, series from India reports higher incidence of abdominal involvement. 3,4 In India, the female to male ratio is as low as $1.6: 1 .^{1}$ The underlying pathologic process is inflammatory and several aetiologic factors having proposed, including spirochetes, mycobacterium tuberculosis, streptococcal organisms, and circulating antibodies due to an autoimmune process. Genetic factors may play a role in the pathogenesis. ${ }^{5}$ Takayasu arteritis has been reported in pediatric patients as young as age 6 months and in adults of every age. In children, Takayasu arteritis is one of the more common aetiologies of renovascular hypertension. ${ }^{6}$ Takayasu arteritis is also known as pulseless disease, occlusive thromboarteriopathy and Martorell syndrome. ${ }^{7}$ The aorta can be involved along its entire length, and although any of its branches can be diseased. The most commonly affected are the 
American College of Rheumatology criteria for the Takayasu's arteritis:

\begin{tabular}{ll}
\hline Criterion & Definition \\
\hline Age at disease one $\leq 40$ years & $\begin{array}{l}\text { Development of symptoms or findings related to Takayasu arteritis at } \\
\text { age } \leq 40 \text { years }\end{array}$ \\
Claudication of extremities & $\begin{array}{l}\text { Development and worsening of fatigue and discomfort in muscles of } \\
\text { one or more extremities while in use, especially the upper extremities. }\end{array}$ \\
Decreased brachial artery pressure & $\begin{array}{l}\text { Decreased pulsation of one or both brachial arteries } \\
\text { Blood pressure difference }>10 \mathrm{mmHg}\end{array}$ \\
Bruit over subclavian arteries or aorta & $\begin{array}{l}\text { Bifference of }>10 \text { mmHg in systolic blood pressure between arms } \\
\text { abdominal aorta. }\end{array}$ \\
Arteriogram abnormality & $\begin{array}{l}\text { Arteriographic narrowing or occlusion of the entire aorta, its primary } \\
\text { branches, or large arteries in the proximal upper or lower extremities, } \\
\text { not due to arteriosclerosis, fibromuscular dysplasia, or similar causes; } \\
\text { changes usually focal or segmental. }\end{array}$ \\
\hline
\end{tabular}

For purposes of classification, a patient shall be said to have Takayasu's arteritis if at least three of these six criteria are present. The presence of any three or more criteria yields a sensitivity of 90.5 percent and a speciality/specificity of 97.8 percent.

subclavian and carotid arteries. ${ }^{8-11}$ Although the most frequent pattern of disease varies geographically. ${ }^{11-13}$ Stenotic lesions found in $>90 \%$ of patients, whereas aneurysm are reported in approximately $25 \% .{ }^{9,10}$ Clinical features are generalized as well as localized. Non specific systemic symptom like fever, loss of weight, headache, fatigue, general weakness, night sweat, anorexia, arthralgia, Ischemic pain are present. Splenomegaly, cervical and axillary lymph adenopathy are sometimes present.

\section{Case History:}

A 37 years old multiparous lady presented with 6 years history of intermittent claudication in right upper and lower limbs. Patient had a history of exertional dysponea initially of NYHA class - I, later progressed to NYHA class - III. She had been suffering from exertional central compressive chest pain radiating to left upper limb for 4 years. During the last 8 months patient felt vertigo without history of unconsciousness, deafness, tinnitus, visual problem or limb weakness.

She had consulted many physicians for her problems and later admitted to NICVD. On examination patient was found anxious with mild pallor and cold periphery. Her pulse was 80 bpm, regular, absent in both upper limbs and low volume in left lower limb. Blood pressure was unrecordable in both upper limbs whilst BP was $180 / 110 \mathrm{mmHg}$ in right lower limb. Right
Carotid, right Subclavian and left renal bruit were present. Precordium revealed normal findings. Investigation revealed - Hb\%-10gm/dL, ESR-80mm in $1^{\text {st }}$ hour, CRP-Positive, CXR-mild cardiomegaly and Echocardiography showed anterior wall hypokinesia with mild LV systolic dysfunction (EF-50\%). Doppler study of upper and lower limb vessel showed reduced velocity at left common carotid artery with no flow at left subclavian artery with retrograde flow at both vertebral arteries.

CT aortogram and carotid angiogram revealed complete occlusion of left common carotid artery, left subclavian artery and narrow brachiocephalic trunk distally. Mild stenosis at proximal part of the right common carotid artery with collaterals forming left vertebral and axillary artery was noted. Coronary Angiogram (CAG) revealed $70 \%$ stenosis at ramus intermedius. Peripheral Angiogram (PAG) revealed non-visualized left common carotid artery and left subclavian artery with 100\% stenosis at right subclavian and $50 \%$ stenosis at right common carotid artery. Left common iliac artery revealed 90\% stenosis (Fig. 1 \& 2).

With this findings patient was diagnosed as a case of Takayasu arteritis with coronary artery disease, Patient was managed with high dose of corticosteroid along with anti-ischaemic management for coronary artery disease. 


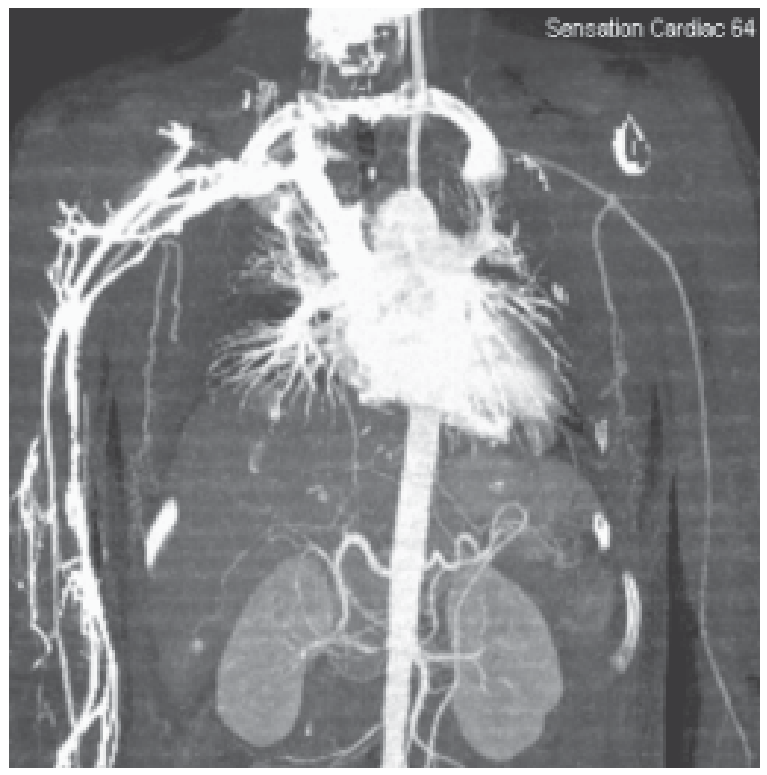

Fig.-1: CT peripheral angiogram shows Takayasu disease involving the both subclavian, right axillary and brachial artery, and ostial involvement of right renal artery.

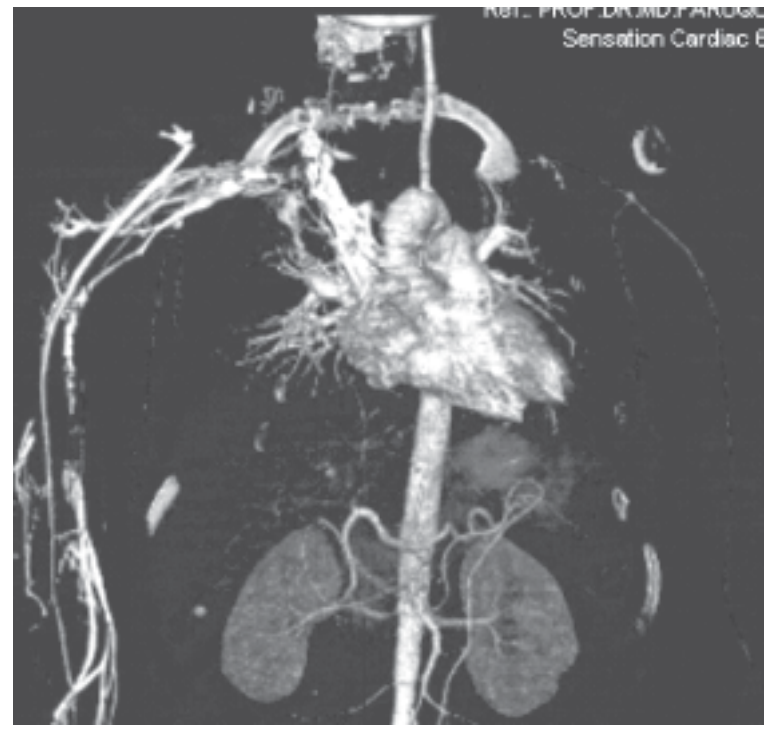

Fig.-2: CT peripheral angiogram shows diffuse vessel involvement in Takayasu disease.

\section{Discussion:}

Takayasu arteritis is an inflammatory disease of largeand medium-sized arteries, with a predilection for the aorta and its branches. Indian origin aortoarteritis is a chronic granulomatous, necrotizing vasculitis, predominantly affecting the aorta with its branches. ${ }^{14}$ The disease is classified based on the site of involvement: ${ }^{15}$
Type I: Aortic arch involvement

Type II: Thoracoabdominal involvement

Type III: Diffuse involvement

Type IV: Pulmonary involvement

Type V: Aneurysmal types

The site of arterial disease determines its clinical presentation. There can be dizziness or syncope due to the decreased perfusion to the brain, which can be aggravated by neck movements. This leads to classical drooping position of the head. A classical bruit can be heard over the stenosed carotids. Cardiac involvement in the form of myocardial infarction, valvular pathology, conduction system block or coronary artery involvement can be seen. Pulmonary vasculitis can lead to pulmonary hypertension and ventilation perfusion abnormalities. The other associated findings are renal artery stenosis and musculoskeletal involvement in the form of rheumatoid arthritis and ankylosing spondylitis. ${ }^{16}$ Ishikawa graded TA depending on the presence of four major complications, i.e., hypertension, retinopathy, aneurysm formation and aortic regurgitation. ${ }^{17}$ Hypertension, the major complication affecting anaesthetic management in patients with TA, is commonly renovascular. It could also result from reduced elasticity and marked narrowing of aorta and major arteries and abnormal function of carotid and aortic sinus baroreceptors. ${ }^{18}$ Measurement of blood pressure and proper documentation of all pulses deserves special attention in such patients. NIBP monitoring using the oscillometric method and pulse oximetry can provide simple and reliable blood pressure readings even in patients with pulseless extremities. ${ }^{19}$

Histologic examination during active stages of the disease discloses a granulomatous arteritis similar to giant cell arteritis and to the aortitis associated with the seronegative spondyloarthropathies and Cogan syndrome. In later stages, medial degeneration, fibrous scarring, intimal proliferation, and thrombosis result in narrowing of the vessel, yet there remains a lack of adequate histopathologic criteria for the differential diagnosis of noninfectious arteritides, including Takayasu disease and giant cell aortitis. ${ }^{20}$ Aneurysm formation is less common than stenosis, but aneurysm rupture is an important cause of death in patients with Takayasu arteritis. Angiographically, the left subclavian artery is narrowed in approximately 90 percent of patients. The right subclavian artery, left carotid artery, and brachiocephalic trunk follow closely in frequency of stenosis. $^{2}$

Corticosteroid therapy appears effective in suppressing inflammation during the active phase, and favorable results have been reported with immunosuppressive and cytotoxic agents, like Cyclophosphamide \& Methotrexate. 
Warfarin, Aspirin and Plasmapheresis may be sometimes helpful. ${ }^{21}$ Operative treatment may be employed to relieve symptoms caused by arterial obstruction, and percutaneous angioplasty and stenting are associated with favorable results. These procedures are best reserved for patients in whom the acute inflammatory stage of the disease has been controlled.

Medical treatment, Balloon Angioplasty with or without Stenting and surgery is the treatment of Takayasu arteritis. Prednisolone is usually used. Cyclophosphamide, Azathioprine, Methotrexate, Dapsone appears to be useful. Aspirin and warfarin reduces the ischemic symptom.

Follow up of this peripheral vascular disease is very essential. Disease course may be slowed by drugs and some times surgical intervention may be helpful. During follow up ESR and CRP may be done which has got the prognostic value.

Prognosis is some times good, usually downhill course. Immunosuppressive drugs have got good prognostic value.

\section{Conclusion:}

Takayasu disease is not very uncommon. It affect usually female. It is disabling disease; gradual downhill course of the diseases makes the patient crippled. Early diagnosis, high dose steroid and vascular intervention or surgical treatment can help the patient to some extent.

\section{Reference:}

1. Jennette JC, Falk RJ, Andrassy K, Bacon PA, Churg J, Gross WL. Nomenclature of systemic vasculities. Proposal of an international consensus conference. Arthritis Rheum. Feb 1994;37(2): 187-92.

2. Elefteriades JA, Olin JW; Halperin JL. Diseases of the Aorta. In: Fuster V, Walsh RA, Harrington RA, editors. Hurst's the Heart. 13th ed. New York: The McGraw-Hill Companies, Inc.;2011. p. 2285-6.

3. Nomano F, Kobayashi Y. Takayasu arteritis beyond pulselessness. Intern Med. Mar 1999;38(3):226-32.

4. Jaun S, Kumari S, Ganguly NK, Sharma BK. Current status of Takayasu arteritis in India. Int J Cardio. Aug 1996;54 Supppl:S111-6.

5. Roberts JR, Stitt R, Shah PA. Takayasu Arteritis. [document on the Internet]. Medscape; 2016 Apr 13 [cited 2016 Apr 20]. Available at: http:// emedicine.medscape.com/article/332378overview\#a5.

6. de Pablo P, Gracia R, Uribe N, et al. Kidney involvement in Takayasu arteritis. Clin Exp Rheumatol. Jan-Feb 2007;25(1 Suppl 44):S10-4.
7. Lupi-Herrere E, Sánchez-Torres G, Marcushamer J, et al. Takayasu arteritis. Clinical study of 107 cases. Am Heart J. 1997;93:94-103.

8. Jaun S, Kumari S, Ganguly NK, Sharma BK. Current status of Takayasu arteritis in India. Int J Cardio. Aug 1996;54 Supppl:S111-6.

9. Kerr GS, Hallahan CW, Giordano J, et al. Takayasu arteritis. Ann Intern Med. 1994 Jun 1;120(11):91929.

10. Mwipatayi BP, Jeffery PC, Beningfield SJ, et al. Takayasu arteritis: Clinical features and management: Report of 272 cases. ANZ J. Surg. 2005;75: 110-7.

11. Ishikawa K, Maetani S. Long-term outcome for $\mathbf{1 2 0}$ Japanese patients with Takayasu's disease: clinical and statistical analysis of related prognostic factors. Circulation. 1994; 90: 1855-60.

12. Sharma BK, Sagar S, Singh AP, Suri S. Takayasu arteritis in India. Heart Vessels Suppl. 1992;7: 3743.

13. Park MC, Lee SW, Park YB, Chung NS, Lee SK. Clinical characteristics and outcomes of Takayasu arteritis: Analysis of 108 patients using standardized criteria for diagnosis, activity assessment and angiographic classification. Scand J Rheumstol. 2005;34: 284-92.

14. DK Satsangi. Surgical experience with aortoarteritis in india. Indian Journal of Thoracic and Cardiovascular Surgery. 2007; 23: 110-5.

15. Moriwaki R, Noda M, Yajima M, Sharma BK, Numano F. Angiology. 1997 May; 48(5):369-79.

16. Stoelting RK, Dierdorf SF: Anesthesia and CoExisting Disease, 4th edition. New York, Churchill Livingstone, 2002.

17. Ishikawa K. Diagnostic approach and proposed criteria for the clinical diagnosis of Takayasu's arteriopathy. J Am Coll Cardiol 1988; 12: 964-72.

18. Sharma BK, Sagar S, Singh AP, Suri S. Takayasu arteritis in India. Heart Vessels Suppl. 1992;7:3743.

19. Chawla R, Kumarvel V, Girdhar KK, et al. Oximetry in pulseless disease [letter]. Anesthesia 1990; 45: 992.

20. Tavora F, Burke A. Review of isolated ascending aortitis: differential diagnosis, including syphilitic, Takayasu's and giant cell aortitis. Pathology. 2006;38:302-8.

21. Arend WP, Michel BA, Bloch DA, et al. The American College of Rheumatology 1990 criteria for the classification of Takayasu arteritis. Arthritis Rheum. 1990;33:1129-34. 